\title{
CONDIÇÃO HUMANA E EFEMERIDADE: ANÁLISE DA PERDA DA EXPERIÊNCIA EM WALTER BENJAMIN Á LUZ DO CONCEITO FREUDIANO DE REPETIÇÃO
}

Hilda Coutinho de Oliveira

Tereza de Castro Callado

\author{
A rua ensurdecedora urrava ao meu redor (...) \\ Uma mulher passou(...) \\ Eu (...) bebia no seu olho, lívido céu que gera o furacão \\ A doçura que fascina e o prazer que mata, \\ um clarão... e a noite depois! -Fugidia beleza, \\ De olhar que me fez renascer, \\ Será que só te verei de novo na eternidade? \\ Tão longe daqui! Tão tarde! Talvez nunca! \\ Pois ignoro para onde vais e não sabes para onde vou. Ó tu que eu teria \\ amado. Ó tu que sabias disto.
}

"A uma passante" em As flores do Mal 1957

Charles Baudelaire

RESUMO

O processo histórico da experiência humana é configurado por meio da reprodução de valores que se estabelecem nas dimensões inconsciente e consciente. Walter Benjamin lamenta o distanciamento do homem desse processo de experiência, intensificado pela interferência da máquina nas relações humanas. A indiferença no que tange à tradição se realiza nos fenômenos de fragmentação, de tirania da imagem enfim, de transformação da cultura em barbárie e consequentemente na perda de espaços para a singularidade. Palavras-chave: filosofia, educação, experiência, sabedoria, cultura

\section{EXPERIENCE AND HUMAN CONDICION}

ABSTRACT

The historical process of the human experience that is shaped through of the reproduction of values that establishes themselves in unconscious and conscious dimensions. The philosopher laments the distant of man of this experience process, that is moved by interference of machine in human relations. The indifference relate to tradition happens in phenomena of fragmentation, transformation of culture in Barbarism and in loss of spaces for the singularities.

Keywords: philosophy, education, experience, sapience, culture.

No ensaio de 1933 "Experiência e Pobreza", Benjamin deixa entrever seu desencantamento diante de um fenômeno que vem modificando as relações do cotidiano entre as pessoas: trata-se da perda da experiência. E o que significaria viver sem experiência na Modernidade? Por que é tão lamentável essa perda? - Teoricamente a fim da experiência representa a falência de um conhecimento que se adensava em forma de sabedoria. E na prática a extinção dos laços que conduziam o patrimônio cultural à substância viva da existência. A Experiência seria a sabedoria acumulada no 
inconsciente e transmitida de uma geração a outra, fosse na família ou na comunidade. Esse saber prático assimilado naturalmente era imprescindível à existência. Mas a tradição foi aos poucos sendo exilada da cultura, pela substituição de novas formas de viver, intensificadas com a assessoria do maquinário, desenvolvido em nome de um bem-estar no âmbito pessoal e profissional, portanto de uma "facilitação" em todos as áreas do agir humano. E a consequência do "milagre" da técnica logo se fez notar, no prejuízo do desaparecimento da sabedoria nutrida no cotidiano simples - conhecimento não livresco, que mingua no espaço da aceleração nas contingências existenciais, promovida pela técnica cada vez mais inventiva e aparelhada no seu percurso em direção a uma utopia prometida pelo progresso. No lugar de prover o homem de maximização de qualidade de vida, o tecnicismo o induz a acompanhar seu ritmo frenético, em uma repetição que engessa os valores da tradição. Benjamin vê no deslocamento para uma existência fictícia, a que chamaríamos de virtual, a dimensão de uma nova forma de miséria, tendo como alvo o "frágil e minúsculo corpo humano (der winzige gebrechliche Menschenkörper)". ${ }^{1}$ Sob a ilusão de uma vida regada pelos vinhos do bem-estar promovido pela tecnologia jaz o patrimônio cultural, com toda sua pluralidade valorativa, descartado em forma de ruína. O que nos resta então a não ser partir da ruína, do fragmento? indaga-se Benjamin, ao tentar dialetizar a ruína em runas, inscrições enigmáticas disponíveis à decifração, com o objetivo de reencontrar a origem. Pois constatar o fim da experiência significa extinguir as referências amealhadas na tradição e configurar uma cultura sem memória e apoio identitário - uma cultura que patina na "logocracia - império dos intelectuais". O logocentrismo, enquanto ideal da cultura, é inequivocamente institucionalizado com o selo da ciência. Sob a palavra de ordem do "logos" desaparecem outros vínculos com o passado, com a história, some igualmente a verdade. E a sabedoria democrática, que independe do poder político-econômico instituído, é expatriada sob a bandeira da própria ciência, a qual nem todos tem acesso. Proliferam estratégias de sobrevivências amorais e aéticas. Em contraponto busca-se uma metamorfose às vezes heroica para a consciência burguesa $^{2}$ nem sempre bem-sucedida, nem sempre visível. Esse conceito é desenvolvido no ensaio Crise do romance, em que Benjamin comenta a Alexanderplatz de Alfred Döblin. No mais das vezes trata-se aqui de um heroísmo anônimo, sofrido, como resistência à nova realidade, onde se prioriza o imediato em detrimento do saber do passado, para se conseguir "a moeda miúda do atual" (um die kleine Münze des "Aktuellen" dafür vorgestreckt zu bekommen.) ${ }^{3} \mathrm{~A}$ pobreza de experiência remete à uma condição de vulnerabilidade e consequente manipulação, que faz de cada um, refém do conformismo e da passividade. Ao definhar a experiência, resta o culto de uma vida mínima, da mera vida (blosses Leben), porque ser bárbaro é ser inculto, insensível, rude, é não sentir compaixão pelo outro. É equivocada a pretensa renovação de ideias nas várias áreas do saber humano, que se abateu sobre o homem subordinando-o ao falso valor da novidade. Diz Benjamin: "a angustiante riqueza de ideias que se difundiu entre, ou melhor, sobre as pessoas com a renovação da astrologia e da ioga, Christian Science e da quiromancia, do vegetarismo e da gnose, da escolástica e do espiritualismo, é o

\footnotetext{
${ }^{1}$ BENJAMIN, "Experiência e Pobreza" in: Magia e Técnica, Arte e Política, Tradução de Sérgio Paulo Rouanet, São Paulo: Brasiliense, 1a Edição, 1985, p. 115.

2 BENJAMIN. "A Crise do romance" in: Magia e Tecnica... Opus cit, p. 59

${ }^{3}$ BENJAMIN, "Erfahrung und Armut" in:_Illuminationen, Frankfurt am Main: Suhkamp, 1977, p. 296.
}

Hilda Coutinho de Oliveira / Tereza de Castro Callado

Doutora em Ciências Médicas e Professora da UFC. Brasileira, residente em Fortaleza - CE E-mail: oliveirahilda@bol.com.br 
reverso dessa miséria. (eine ganz neue Armseligkeit ist mit dieser ungeheuren Entfaltung der Technik über die Menschen gekommen. Und von dieser Armseligkeit ist der beklemmende Ideenreichtum, der mit der Wiederlebung von Astrologie und Yogaweisheit, Christian Science und Chiromancie, Vegetarismus und Gnosis, Scholastik und Spiritismus unter - oder vielmehr über - die Leute kam, die Kehrseite. $)^{4}$ O tempo da barbárie é caracterizado pelo retrocesso, pela repetição do sempre-igual (das Immer-gleiche) estimulado pela lógica do capital e direcionada ao poderio dos mesmos, no cenário fantasmagórico da Metrópole, com sua feição carnavalesca para encobrir o aspecto dantesco da extorsão. Benjamin se pergunta: "Então, de que vale todo o patrimônio cultural se a experiência não o vincula mais a nós? (Denn was ist das ganze Bildungsgut wert, wenn uns nicht eben Erfahrung mit ihm verbindet?) $\mathrm{Na}$ diagnose de Benjamin resta o bárbaro, que admite, assumindo uma atitude de despojamento quase estoico, o recomeço a partir do pouco. Com essa afirmação Benjamin cita o exemplo de Descartes e Einstein. A mesma ideia de um despojamento como condição para viver melhor se encontra na imagem de "Der destruktive Charakter, do livro imagens do pensamento (Denkbilder), para quem a necessidade de ar puro e espaço é maior que todo ódio (Sein Bedürfnis nach frischer Luft und freiem Raum ist stärker als jeder Hass) ${ }^{5}$ Tudo leva a crer que se trata, aqui, do ódio revolucionário. Mais uma lição que Benjamin nos dá sobre os efeitos corrosivos da atitude radical, postura que norteou suas próprias escolhas. No lugar de assumir uma revolução anárquica, os mecanismos que o filósofo articula para se desviar dos artifícios da dominação ideológica se espalham em reflexões, nos ensaios, com o vigor fluido da inteligência, sobretudo da presença de espírito (Geistesgegenwart) e da boa vontade, como bom estudioso do Kantismo. No status quo de uma realidade viciada pelas relações de poder, onde o homem que nasce livre, se vê subordinado, a crítica de Benjamin vem minando os espaços do controle totalitário, sem se iludir diante de sua feição embrionária. Já na infância o brinquedo imposto por “ bolorentas especulações dos pedagogos", ${ }^{6}$ não permite que a criança explore sua imaginação. No fragmento "Canteiro de Obras (Baustelle)" de Einbahnstrasse : "elas (as crianças) são capazes de ver o que o pedagogo não percebe: que a terra está repleta dos mais incomparáveis objetos de atenção e exercício infantis. E dos mais apropriados (dass de Erde voll von den unvergleichlichsten Gegenständen kindlicher Aufmerksamkeit und Übung ist. Von den bestimmtesten.) ${ }^{7}$ Nada excede a riqueza de objetos lúdicos e educativos do mundo que podem ser construídos pela infância. É o próprio Benjamin que fala na obra das passagens de uma indestrutibilidade da natureza que reage trazendo renovadamente, na criação o inteiramente novo. Essa ideia está bem presente no seu pensamento. Quanto a criança, sim, ela é capaz de trazer o inteiramente novo, como indicam as ideias freudianas no texto Além do princípio do Prazer. Enquanto o adulto imerge na realidade fantasmagórica do sempre igual, pela acomodação, a criança, segundo Freud, repetiria situações traumáticas de forma lúdica, ${ }^{8}$ processo que seria naturalmente saudável e

\footnotetext{
${ }^{4}$ BENJAMIN< Illuminationen . Opus cit, p.a 292;

${ }^{5}$ BENJAMIN, “Der destruktive Charakter in:__lluminationen, Opus cit, p. 289.

${ }^{6}$ BENJAMIN, "Canteiro de Obras" in:__ Rua de Mão Única, tradução de Rubens Rodrigues Torres Filho e José Carlos Martins Barbosa, 1ạ Edição, São Paulo: Brasiliense, 1987, p. 18.

7 BENJAMIN, “Baustelle - Einbahnstrasse” in:_Kleine Prosa, Baudelaire-Übertragungen, Band IV-1, Frankfurt am Main: Suhrkamp Verlag, 1991, Seite. 93.

${ }^{8}$ FREUD, Além do princípio do prazer, Rio de Janeiro: Imago Editora, 1996, p. 46
} 
terapêutico, e que poderia lhe propiciar a cura: ${ }^{9}$ Diz Freud: "se o médico examina a garganta de uma criança ou faz nela alguma pequena intervenção, podemos estar inteiramente certos de que essas assustadoras experiências serão tema da próxima brincadeira; contudo não devemos quanto a isso, desprezar o fato de existir uma produção de prazer provinda de outra fonte". Não devemos menosprezar sua criatividade. Freud continua: "quando a criança passa da passividade da experiência para a atividade do jogo, transfere a experiência desagradável para um de seus companheiros de brincadeira e, dessa maneira, vinga-se num substituto; Todavia, decorre desse exame que não há necessidade de supor a existência de um instinto imitativo especial para fornecer um motivo para a brincadeira". (Wenn der Doktor dem Kind in den Hals geschaut oder eine kleine Operation an ihm ausgeführt hat, so wird dies erschreckenden Erlebnis ganz gewiss zum Inhalt des nächstes Spieles werden, aber der Lustgewinn aus anderer Quelle ist dabei nicht zu übersehen. Indem das Kind aus dem Passivität des Erlebens in die Aktivität des Spielens übergeht, fügt es einem Spielgefährten das Unangehneme zu, das ihm selbst widerfahren war und rächt sich so na der Person dieses Stellvertreters; Aus diesen Erörterungen geht immerhin hervor, dass die Annahme eines besonderen Nachahmungstriches als Motiv des Spielens überflüssig ist”. 10 As manifestações de uma compulsão à repetição (que descrevemos como ocorrendo nas primeiras atividades da vida mental infantil, bem como entre os eventos do tratamento psicanalítico) representam em alto grau um caráter instintual (Triebhaft). Com o adestramento e a docilização do corpo próprios do aculturamento, essa eclosão da espontaneidade se diluiria. A criança nunca se cansa de ouvir repetido aquilo que lhe causou prazer, seja uma história ou um jogo. Na repetição ela desenvolve sua capacidade criativa e imaginativa, o que não ocorre com o adulto, que dificilmente lerá o mesmo livro, embora tenha se deliciado com ele. "No caso da brincadeira parece que percebemos que as crianças repetem experiências desagradáveis pela razão adicional de poderem dominar uma impressão poderosa muito mais completamente de modo ativo do que poderiam fazê-lo simplesmente experimentando-a de modo passivo". Cada nova repetição parece fortalecer a supremacia que buscam". ${ }^{11}$ Já no adulto inexiste essa capacidade de repetir que objetiva a libertação do objeto repetido, como na criança. A repetição adulta tem outra origem, ela está relacionada a um estado de passividade como nos ensina Freud: "Parece que um instinto é um impulso, inerente à vida orgânica, a restaurar um estado anterior de coisas, impulso que a entidade viva foi obrigada a abandonar sob a pressão de forças perturbadoras externas, ou seja, é uma espécie de elasticidade orgânica, ou, para dizê-lo de outro modo, a expressão da inércia inerente à vida orgânica". ${ }^{12}$ Conhecendo a informação de que esse estado de passividade parece

\footnotetext{
${ }^{9}$ Sobre a repetição na criança, "nada (...) contradiz o princípio do prazer: a repetição, a reexperiência de algo idêntico, é claramente, em si mesma, uma fonte de prazer. FREUD , Além do princípio do Prazer, idem, pp. 27-28

${ }^{10}$ FREUD, Jenseits des LUstprinzips, Wien, Leipzig, Zürich: Internationaer Psychoanalytischer Verlag, G.M.B.H, 1921. Seite 13.

${ }^{11}$ Jede neuerliche Wiederholung scheint diese angestrebte Beherrschung zu verbessert FREUD, Jenseits des Lustprinzips, Opus cit, aSeite 33.

12 Ein Trieb wäre also ein dem belebten Organischen innewohnender Drang zur Wiederherstellung eines früheren Zustandes, welchen dies Belebte unter dem Einflusse äusserer Störungengskräfte aufgeben musste, eine Art von organischer Elastizität, oder wenn man will, die äusserung der Trägheit im organischen Leben. FREUD, Jenseits des Lustprinzips, Opus cit, Sete- 34-35.
}

Hilda Coutinho de Oliveira / Tereza de Castro Callado

Doutora em Ciências Médicas e Professora da UFC. Brasileira, residente em Fortaleza - CE E-mail: oliveirahilda@bol.com.br

Pós-Doutora pela USP, Professora da Universidade Estadual do Ceará. Brasileira, residente em Fortaleza - CE, E-mail: mterecall@yahoo.com.br 
ter uma origem na vida orgânica, não podemos deixar de associar esse conhecimento ao conceito de conformismo que Benjamin desenvolve paralelo a sua teoria política, tanto em Origem do drama barroco alemão - onde a teoria da soberania é estruturada sobre a capacidade de decidir do monarca, sobretudo em um estado de exceção - como na tese 11 de Sobre o conceito da história (Über den Begriff der Geschichte), em que Benjamin atribui ao conformismo o motivo do colapso da classe operária alemã, posteriormente ao condicionamento de suas ideias políticas e econômicas. Uma vez que Benjamin já não insiste em uma categoria de sujeito, por questões obvias, no contexto político vivido, esse espaço pode ser magistralmente ocupado pela habilidade para decidir do ser político (Entschlussfähigkeit). Para Benjamin a incapacidade para se tomar uma atitude e se deixar levar pelo conformismo, é causa de catástrofe. Mas essa habilidade para a decisão, sobretudo revolucionária, no ponto de vista benjaminiano - e em que ele estrutura a exigência de uma tematização política - contaria a princípio, com a capacidade de lidar com os fatos, o que só é conseguido com a sabedoria peculiar à experiência. Aqui teríamos que fazer um aparte para elucidar certas questões levantadas por Benjamin com relação à compulsão à repetição no adulto e a naturalidade da repetição na criança e seu efeito de neutralizar situações traumáticas, no mais das vezes, no exercitar de sua faculdade mimética, repetindo, a sua maneira, uma vida exterior a ela, a dos adultos que a circundam. Diante da compulsão do adulto à repetição, que é detectada na configuração da natureza fantasmagórica da Metrópole, poderíamos entender o arrefecimento da experiência como uma função determinante? É o que tentaremos investigar. Pretendendo avançar um pouco nesse processo, a falência que teríamos a lamentar igualmente, com relação ao fim da experiência, constituída como estofo da arte de narrar, seria a do seu ponto fulcral - a memória. Para Benjamin a memória é "a mais épica das faculdades (das Gedächtnis ist das epische Vermögen vor allen anderen)". ${ }^{13}$ Portanto a memória estaria aliada à sabedoria para estruturar a narrativa. Para Benjamin a arte de narrar definha porque "a sabedoria - o lado épico da verdade, encontra-se em extinção (die Kunst des Erzählens neigt ihrem Ende zu, weil die epische Seite der Wahrheit, die Weisheit, ausstirbt)." Se a sabedoria está em extinção, desapareceriam igualmente os elos do manancial da tradição que alimentaria a verdade. Com a impossibilidade de se recuperar a história de um indivíduo na sua integra restariam seus parcos vestígios: $O$ homem passa pela terra sem deixar vestígios, já diagnosticava a dramaturgia do século XVII, registrada no Trauerspielbuch. É essa a realidade a que Benjamin tenta resistir apelando para a vivência humana diante do exílio de uma imagem do homem, na sua inteireza, na capacidade de exercitar o corpo, em uma totalidade. A insistência nessa temática percorre o ensaio de 1933 com a menção ao frágil e minúsculo corpo humano" para se adensar em "O Narrador" onde se definiria o resultado da preciosa arte de narrar pelo cultivo de uma habilidade harmônica entre matéria e espírito (outra transgressão benjaminiana à tradição como é de seu feitio), em que interagiriam igualmente a alma e o corpo do narrador. Benjamin diz: na arte de narrar, a alma, o olho, a mão estariam inscritos no mesmo campo (Seele, Auge und Hand sind (...) in einen und denselben Zusammenhang eingebracht). Trata-se aqui de interação, consonância. Nesse cruzamento criativo estando alma, olho e mão em uníssono, definir-se-ia uma prática (ineinanderwirkend bestimmen sie eine Praxis). Essa

${ }^{13}$ BENJAMIN. Aufsätze, Essays, Vorträge, Band II-2, 1991, Seite, 453.

Hilda Coutinho de Oliveira / Tereza de Castro Callado

Doutora em Ciências Médicas e Professora da UFC. Brasileira, residente em Fortaleza - CE, E-mail: oliveirahilda@bol.com.br

Pós-Doutora pela USP, Professora da Universidade Estadual do Ceará. Brasileira, residente em Fortaleza - CE, E-mail: mterecall@yahoo.com.br 
prática deixou de nos ser familiar (Uns ist diese Praxis nicht mehr geläufig). ${ }^{14}$ Benjamin continua: "o papel da mão no trabalho produtivo tornou-se mais modesto, e o lugar que ela ocupava durante a narração está agora vazio". Portanto era o corpo na sua inteireza que interagia na elocução da narrativa. Assim definido, "o narrador figura entre os mestres e os sábios". Pois a narrativa sustentava os elos da tradição de uma totalidade, para o homem. Unia o passado ao presente, urdia uma rede de comunicação conduzindo o conhecimento em forma de conselho. O conselho tecido na substância viva da existência, tinha um nome: sabedoria (Rat, in den Stoff belebten Lebens eingewebt, ist Weisheit). ${ }^{15}$ Leskov reconhecia o teor artesanal da arte de narrar. E ao descrever a "imagem espiritual do mundo dos artífices", Valéry coloca o narrador no centro dessa atividad,“, remete-a à perfeição das criações da natureza, como as pérolas que produziam seus admiráveis elementos com tenacidade, virtude e sem limite de tempo. Os relatos do narrador remetem assim, à história natural'. Benjamin compreende que a extinção de um modus vivendi através da transmissão de sabedorias entre as gerações provocou transformações avassaladoras no aparelho psíquico das pessoas, forçando-as a resistência com outros mecanismos - os perceptivos. Assim uma vez extinta a experiência resta ao homem a vivência, a experiência fugaz, passageira, como a que foi descrita como epígrafe do frontispício desse trabalho, e sua dedicatória ao poema "A uma passante" de Baudelaire. "Parece que a humanidade está cansada de experiências duradouras", conclui o filósofo Walter Benjamin no ensaio Experiência e Pobreza. Em contraponto tenta-se atulhar o vazio com mercadorias e mercadoria - signo na neurose, característica da repetição. Sob a luz de holofotes, sinais luminosos, pisca-piscas, alertas, buzinas e barulhos ensurdecedores de máquinas e construções jaz "o minúsculo corpo" do homem que precisa estar atento se não quiser ser esmagado no trânsito infernal da Metrópole. Não é por acaso que Benjamin identifica a condição de vida do seu tempo na provocação sibilina das vanguardas dadaísta, concretista, surrealista. Cada uma a seu modo sinaliza o fim de uma era de totalidades. Essas estéticas dão um ponto final ao limite, ao contorno, assimilam o despedaçamento, a fragmentação enquanto tônus da estética. Pois é preciso sobreviver a qualquer custo, diante do choque, nos labirintos da cidade. Mas a cidade tem ironicamente seu lado "auspicioso": sua fantasmagoria. Ela embriaga, esconde a aceleração, a transformação do homem em um autômato, suas neuroses, massageia seu Ego, convida-o a narcotizar-se com seus fluidos mágicos, a deixar-se lassivamente seduzir com seu brilho sedutor. Faz de qualquer um, um flâneur. Ela mesma tem um aliado inconteste: o mundo mítico, o sonho, mundo bem realizado na lógica do progresso. Não é por acaso que o século XVIII cultivou a ironia romântica, pois o conto de fadas desse tempo: "nos revela as primeiras medidas tomadas pela humanidade para libertar-se do pesadelo mítico (das Märchen gibt uns Kunde von den frühesten Veranstaltungen, die die Menschheit getroffen hat, um den Alp, den der Mythos auf ihre Brust gelegt hatte, abzuschütteln)" ${ }^{16} \mathrm{O}$ conto de fadas dos irmãos Grimm (das Märchen) ensinava às crianças que o mais aconselhável é enfrentar as forças do mundo mítico com astúcia e arrogância (das Ratsamste, so hat das Märchen vor Zeiten die Menschheit gelehrt, und so lehrt es noch heut die Kinder, ist

\footnotetext{
${ }^{14}$ BENJAMIN, Aufsätze, Essays, Vorträge, Band II- 2, 1991, Seite, 464.

${ }^{15}$ BENJAMIN, Ausätze, Essays.... Opus cit, Seite 442.

${ }^{16}$ BENJAMIN, Ibidem, Seite 458.
}

Hilda Coutinho de Oliveira / Tereza de Castro Callado

Doutora em Ciências Médicas e Professora da UFC. Brasileira, residente em Fortaleza - CE, E-mail: oliveirahilda@bol.com.br 
den Gewalten der mytischen Welt mit List und mit Übermut zu begegnen). ${ }^{17}$ No entanto essa sabedoria que minada do inconsciente para o consciente em forma de um conhecimento prático para a vida irá empalidecer para dar lugar a um puro envolvimento, a partir do encantamento com a técnica. Com o fim da experiência que era capaz de canalizar energias do inconsciente para a consciência o recalque dessas energias do inconsciente produziria neuroses, cuja característica seria a repetição. Ora, a repetição encontra um espaço fértil para sua ocorrência na forma de compatibilizar a neurose do desempenho humano a todo custo, com a marcha de uma razão histórica rumo à "perfectibilidade do gênero humano". Para isso foi concebido e gerado pela ciência o que se chama hoje de progresso. Mas esse "remédio", se é capaz de sanar as necessidades da cultura, tem seus efeitos colaterais, no estímulo ao desejo: a compulsão ao consumo seria uma delas. A lógica do lucro é deixar que circulem os objetos de desejo alimentando dessa forma uma necessidade cultivada artificialmente. A intensificação de lógicas de facilitação de vida, com a dissolução da família com o desaparecimento da autoridade, o deslocamento do estímulo e da competência para ensinar, da autoridade da figura paterna para o estado, com a coerção e o autoritarismo de quaisquer sistemas ideológicos, totalitários políticos ou religiosos cujo objetivo visa a angariar seguidores treinados pelo estado, a prática de projetos arquitetônicos para garantir a segurança à individualidade que acabam desumanizando as cidades, e enfim a experiência da substituição de materiais naturais como a madeira pelos artificiais, como o vidro tem tudo a ver com o que o indivíduo está se tornando: de uma acessibilidade ilusória, que não deixa passar o calor humano e onde as experiências não grudam. A cultura asséptica do vidro, possibilitada pelo tecnicismo seria uma grande aliada do status quo atual. A aura da técnica chega até a substituir a aura religiosa. Ela faz a existência bastar aparentemente a si mesma, disfarçando as energias recalcadas do inconsciente. Sabe-se que as trocas afetivas da dimensão humana possibilitam a construção de uma história do indivíduo. Na ausência delas, os sujeitos psicológicos nos quais se sobressai o caráter fantasmático do inconsciente, motivado pela neurose da falta são movidos à_repetição, tecem sentidos no contexto social cuja compreensão depende da valorização de desejos, fantasias, pulsões de vida e de morte, nos ensina Freud. Assim, sua disciplina - a psicanálise - abrangeria um método investigativo que evidenciaria o significado inconsciente das palavras, ações e produções imaginárias de um ser humano. ${ }^{18} \mathrm{O}$ método se baseia em associações livres que garantem a validade da interpretação. Esta pode também referir-se a produções humanas, como ressaltam Laplanche e Pontalis, (1988). ${ }^{19}$ A psicanálise constituiria também um método psicoterápico com base nessa investigação e configurado pela interpretação da resistência, transferência e desejo, sendo o inconsciente um conjunto de conteúdos recalcados, aos quais foi recusado o aceso ao sistema pré-consciente-consciente por

\footnotetext{
${ }^{17}$ BENJAMIN, Ibidem, Seite 458.

${ }^{18}$ A metapsicologia de Freud (1915) ou a psicologia por ele fundada, considera os pontos de vista dinâmico (segundo o qual os fenômenos psíquicos resultariam do conflito e da composição de forças pulsionais) , tópico (segundo o qual o aparelho psíquico diferencia-se em 1. Inconsciente, préconsciente e consciente, e 2 . Id, ego e superego) e econômico (o qual indica que os processos psíquicos consistem na circulação e repartição de uma energia pulsional quantificável - que poderia aumentar, diminuir ou ter equivalências).

${ }^{19}$ LAPLANCHE e PONTALIS. Vocabulário de psicanalise. Tradução do original francês de 1967 por Pedro Tamen, 10a Edição, São Paulo: Martins Fontes, 1988, 707 p.
}

Hilda Coutinho de Oliveira / Tereza de Castro Callado

Doutora em Ciências Médicas e Professora da UFC. Brasileira, residente em Fortaleza - CE, E-mail: oliveirahilda@bol.com.br

Pós-Doutora pela USP, Professora da Universidade Estadual do Ceará. Brasileira, residente em Fortaleza - CE, E-mail: mterecall@yahoo.com.br 
conta do recalcamento. ${ }^{20}$ Intenções conscientes ou inconscientes (a maioria delas) determina cada evento mental, ${ }^{21}$ Freud vislumbrava a alma no inconsciente e sua psicanálise decifra os significados subjacentes aos sintomas humanos para facilitar enredos de vidas mais plenas. A teoria de Freud seduz por desvelar a riqueza subjetiva da vida afetiva, sobretudo sexual. ${ }^{22}$ Espanta pela tentativa de tentar decifrar a alma do homem em meio a contradições, segredos, amores, ódios, conflitos e angústias que integram a instigante e fugidia complexidade escondida no inconsciente, a qual somente se insinua através de traços indiciosos. É sábio portanto equacionar a vida, problematizar o que já está estruturado, atentar para seus signos dispersos, sonhar com uma realidade sem rudezas, repensar e recriar outros rumos possíveis e melhores de existência. Tomando conhecimento do inconsciente com o movimento surrealista Benjamin investiga no homem estratégias para buscar a perpetuação de sua própria história, e as encontra entrelaçadas de memórias fundadas no inconsciente e que instigam à sabedoria. A conclusão a que Benjamin nos leva, com a apresentação da imagem de um caráter destrutivo, cuja necessidade básica é espaço e ar puro, e cuja natureza apolínea lhe aponta uma encruzilha com uma diversidade de opções, ao invés de uma via de mão única (Einbahnstrasse) é arrematada no ensaio O Narrador onde nos relata sobre a longevidade da arte de narrar, já exercitada por Homero. No conhecimento traçado pelo inconsciente que circula de uma geração a outra em forma de sabedoria efetiva-se o grande elo da memória como Mnemosyne deusa da reminiscência para os antigos. Ela funda a cadeia da tradição. Ela corresponde à musa épica no sentido mais amplo. Ela inclui todas as variedades da forma épica. Entre elas encontra-se em primeiro lugar a encarnada pelo narrador. Como nos contos de Scherazade, a virtude é a inconclusão, que aguça a curiosidade, permitindo a cada ouvinte interpretar o conto e sobretudo a continuá-lo. Essa faixa de ausência é vital para a plenitude da narrativa e de onde ela retira sua sabedoria -, abandonar-se a pluralidade de decifrações, deixar-se enriquecer com a colaboração de cada ouvinte e futuro narrador. Dessa forma despedindo a homogeneização da realidade gerida pelo padrão e fugindo da neutralidade para ceder espaço à riqueza das diferenças, ao eliminar a rigidez do arquétipo, a arte de narrar faria justiça à singularidade que se esconde em cada inconsciente. Será que Benjamin, ao observar no trabalho artesanal de amontoar recortes e pedaços de imagens da técnica fílmica, não teria visto nela a atividade remota de um narrador ao reagrupar fios narrativos em uma lógica prática para conduzir sua existência e de seus ouvintes? Se empregada nos dias de hoje essa sabedoria prática estaria pronta a desestabilizar a violência corrosiva do controle e da dominação da

\footnotetext{
${ }^{20}$ Os conteúdos do inconsciente representam as pulsões e são regidos pelo processo primário quando a energia psíquica se escoa livremente, tendendo a reinvestimentos plenos das representações associadas às vivências de satisfação que constituem o desejo. Os processos psíquicos inconscientes, atemporais, atuam na conduta do indivíduo apartados do âmbito da consciência, mas emergem nos sonhos, atos falhos, sintomas neuróticos e estados psicóticos quando a consciência não está atenta. Há determinismo psíquico, continuidade, nexos na vida mental. Causalidades referenciam pensamentos, memórias, sentimentos e ações. Conf. FREUD, O Inconsciente, Metapsicologia, Tradução de Jayme Salomão, Rio de Janeiro: Imago, 1974.

${ }^{21}$ FREUD. O Inconsciente, Metapsicologia, Tradução de Jayme Salomão, Rio de Janeiro: Imago, 1974.

${ }^{22}$ Ver, a respeito da relação, na Artnouveau, entre estética e esterilidade feminina, o ensaio "Jugendstil e o mito fascista do belo: oração fúnebre à crítica". DE CASTRO CALLADO, Tereza. in:_Cadernos Walter Benjamin n. 06, jan/jun de 2011, acessível no site: www.gewebe.com.br
}

Hilda Coutinho de Oliveira / Tereza de Castro Callado

Doutora em Ciências Médicas e Professora da UFC. Brasileira, residente em Fortaleza - CE, E-mail: oliveirahilda@bol.com.br

Pós-Doutora pela USP, Professora da Universidade Estadual do Ceará. Brasileira, residente em Fortaleza - CE, E-mail: mterecall@yahoo.com.br 
natureza a que se atribui o modus vivendi responsável pela repetição e a automatização. Ou esse bem valioso do homem - a percepção (Wahrnehmung), que se intensifica e aguça, com a substituição da experiência (Erfahrung) pela vivencia com o choque (Chockerlebnis), na cultura da barbárie, não teria força suficiente, ela própria, de fazer da violência a argamassa e a matéria prima para uma imagem dialética? Não há dúvida de que Benjamin guardou esse conhecimento. Pois o comentário sobre a reprodutibilidade técnica da arte, exemplificada no cinema, aponta nos filmes grotescos a possibilidade de uma "hilaridade coletiva", consequentemente da "eclosão precoce e saudável da psicose de massa". E o "índice impressionante dos perigos que ameaçam a humanidade, resultantes das repressões que a civilização traz consigo", guardaria sua dialética: a oportunidade de uma "explosão terapêutica do inconsciente". ${ }^{23}$

\section{REFERÊNCIAS}

BENJAMIN, Walter. Ursprung des deutschenTrauerspiels, Frankfurt am Main: Suhrkamp Verlag, 1991.

BENJAMIN, Walter. Illuminationen, ausgewählte Schriften, Frankfurt am Main:

Suhrkamp Verlag, 1999;

BENJAMIN, Walter. Gesammelte Schriften, Frankfurt am Main: Suhrkamp Verlag, 1991.

BENJAMIN, Magia e Técnica, Arte e Política, Tradução de Sérgio Paulo Rouanet, São Paulo: Brasiliense, 1985.

DE CASTRO CALLADO, Tereza. Walter Benjamin. A Experiência da Origem, Fortaleza: EDUECE. 2006.

DE CASTRO CALLADO, Tereza, "As metamorfoses da consciência burguesa e a imagem dialética (Dialektik im Stillstand)" in:_Cadernos Walter Benjamin 04, Jan/Jun 2010, acessível no site: www.gewebe.com.br

DE CASTRO CALLADO, Tereza, "Jugendstil e o mito fascista do belo: oração fúnebre à crítica in:_Cadernos Walter Benjamin n. 06, Jan/Jun de 2011, acessível no site:

www.gewebe.com.br

FREUD, Sigmund. O Inconsciente, Metapsicologia. V. XIV, Tradução do original por Jayme Salomão, Rio de Janeiro: Imago, 1974.

FREUD, Sigmund. Conferencias introdutórias sobre Psicanálise. Tradução de Jayme Salomão, Rio de Janeiro: Imago, 1972.

LAPLANCHE, J. e PONTALIS, J.B. Vocabulário de psicanálise, Tradução do original francês de 1967 por Pedro Tamen. 10ª Edição, São Paulo: Martins Fontes, 1988, 707 p.

FREUD, Sigmund. Jenseits des Lustprinzips, Wien, Leipzig, Zürich: Internationaler Psychoanalytischer Verlag, G.M.B.H., 1921.

FREUD, Sigmund, Para além do princípio do prazer, Tradução do alemão e d inglês sob a direção de geral de Jayme Salomão, Rio de Janeiro: Imago Editora, 1996.

\footnotetext{
${ }^{23}$ BENJAMIN. "A obra de arte na era de sua reprodutibilidade técnica" in:__ Magia e técnica, arte e política, Tradução de Sérgio Paulo Rouanet, São Paulo: Brasiliense, 1985, p.190.

Hilda Coutinho de Oliveira / Tereza de Castro Callado

Doutora em Ciências Médicas e Professora da UFC. Brasileira, residente em Fortaleza - CE, E-mail: oliveirahilda@bol.com.br

Pós-Doutora pela USP, Professora da Universidade Estadual do Ceará. Brasileira, residente em Fortaleza - CE, E-mail: mterecall@yahoo.com.br
} 